Keywords: tritium facility, pumps, polymer, oil, degradation

Retention: Permanent

\title{
Normetex Pump Alternatives Study
}

Elliot A. Clark

Materials Science \& Technology

25 April 2013

Savannah River National Laboratory Savannah River Nuclear Solutions, LLC Aiken, SC 29808

Prepared for the U.S. Department of Energy under

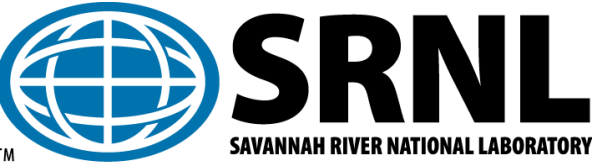
contract number DE-AC09-08SR22470. 


\section{DISCLAIMER}

This work was prepared under an agreement with and funded by the U.S. Government. Neither the U.S. Government or its employees, nor any of its contractors, subcontractors or their employees, makes any express or implied:

1. warranty or assumes any legal liability for the accuracy, completeness, or for the use or results of such use of any information, product, or process disclosed; or

2. representation that such use or results of such use would not infringe privately owned rights; or

3. endorsement or recommendation of any specifically identified commercial product, process, or service.

Any views and opinions of authors expressed in this work do not necessarily state or reflect those of the United States Government, or its contractors, or subcontractors.

\section{Printed in the United States of America \\ Prepared for U.S. Department of Energy}


SRNL-STI-2013-00325

\section{EXECUTIVE SUMMARY}

A mainstay pump for tritium systems, the Normetex scroll pump, is currently unavailable because the Normetex company went out of business. This pump was an all-metal scroll pump that served tritium processing facilities very well. Current tritium system operators are evaluating replacement pumps for the Normetex pump and for general used in tritium service. An all-metal equivalent alternative to the Normetex pump has not yet been identified.

1. The ideal replacement tritium pump would be hermetically sealed and contain no polymer components or oils. Polymers and oils degrade over time when they contact ionizing radiation.

2. Halogenated polymers (containing fluorine, chlorine, or both) and oils are commonly found in pumps. These materials have many properties that surpass those of hydrocarbon-based polymers and oils, including thermal stability (higher operating temperature) and better chemical resistance. Unfortunately, they are less resistant to degradation from ionizing radiation than hydrocarbon-based materials (in general).

3. Polymers and oils can form gaseous, condensable (HF, TF), liquid, and solid species when exposed to ionizing radiation. For example, halogenated polymers form $\mathrm{HF}$ and $\mathrm{HCl}$, which are extremely corrosive upon reaction with water. If a pump containing polymers or oils must be used in a tritium system, the system must be designed to be able to process the unwanted by-products. Design features to mitigate degradation products include filters and chemical or physical traps (eg. cold traps, oil traps).

4. Polymer components can work in tritium systems, but must be replaced regularly. Polymer components performance should be monitored or be regularly tested, and regular replacement of components should be viewed as an expected normal event. A radioactive waste stream must be established to dispose of used polymer components and oil with an approved disposal plan developed based on the facility location and its regulators. Polymers have varying resistances to ionizing radiation - aromatic polymers such as polyimide Vespel ${ }^{\circledR}$ and the elastomer EPDM (ethylene propylene diene monomer) have been found to be more resistant to degradation in tritium than other polymers.

This report presents information to help select replacement pumps for Normetex pumps in tritium systems. Several pumps being considered as Normetex replacement pumps are discussed. 


\section{CONTENTS}

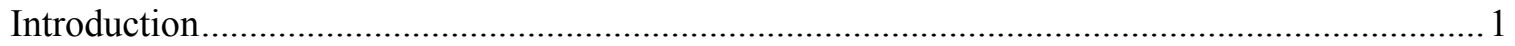

Studies of Effects of Tritium on Polymers........................................................................................ 1

Considerations for Using Polymers in Tritium Systems................................................................ 1

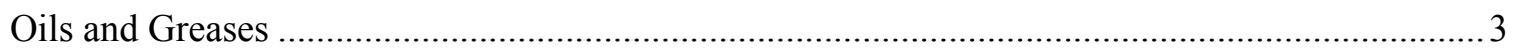

Mechanical Pumps Being Considered ............................................................................ 3

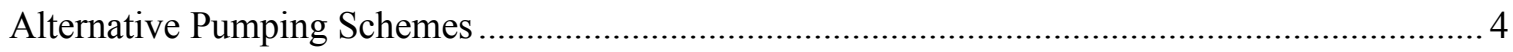

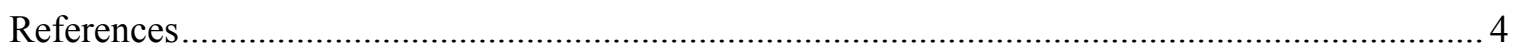




\section{Introduction}

For more than a decade, a type of scroll pump manufactured by the Normetex Company (France) has been a mainstay for tritium processing systems. Parts of this pump that contact the working fluid are entirely made of metal - the pump has both no polymer seals and no oil. Since polymers and oils degrade when exposed to ionizing radiation, a pump with no polymers or oils is advantageous. Recently, the Normetex company has gone out of business and these all-metal scroll pumps are now unavailable.

New tritium processing systems must use pumps of some kind, and a similar all-metal scroll pump has not been found. Because of this, pumps employing polymers or oil must be chosen, at least for the foreseeable future. This report gives an overview of radiation damage of polymers, discusses how polymers are commonly employed in pumps, and recommends mitigating system features to prevent degradation products from organic polymers and oils from entering and possibly harming tritium processing systems. Current tritium handling systems do employ solid polymer components, mainly as seals such as valve stem tips and packing and O-rings. These components can be employed safely as long as it is recognized that these components will degrade over time and thus require regular testing and preventative maintenance programs to monitor their performance. Also, oil-based pumps have been successfully employed in tritium processing systems.

\section{Studies of Effects of Tritium on Polymers}

There have been several recent studies of the effects of tritium exposure on polymers including thermoplastics such as ultrahigh molecular weight polyethylene (UHMW-PE), polytetrafluoroethylene (PTFE or Teflon $\left.{ }^{\circledR}\right)$, and the polyimide Vespel ${ }^{\circledR}[1,3]$; the elastomer ethylene-propylene-diene monomer (EPDM) [2, 3, 4]; and electrically conducting polymers [4]. These studies have exposed samples of the various polymers in closed containers to initially one atmosphere of tritium gas. These studies reveal that samples of polymers having a single carbon-halogen bond, called the chloro-fluoro-carbon family, are degraded by tritium after only about six months exposure (PTFE). UHMW-PE, having mainly linear C-H and $\mathrm{C}-\mathrm{C}$ bonds, is significantly more resistant to tritium gas than halogenated polymers. Polymers having aromatic groups, such as Vespel ${ }^{\circledR}$, are in turn more resistant to tritium exposure than UHMW-PE. The elastomer ethylene-propylene-diene monomer (EPDM) is quite resistant to ionizing radiation in general, and to tritium exposure specifically.

UHMW-PE produces significant amounts of protium gas when exposed to tritium [1]. This is expected based on the known production of protium from all types of polyethylene when exposed to ionizing radiation. When PTFE was exposed, the total gas pressure of the closed containers decreased [1], indicating the formation of $\mathrm{TF}$ which adheres to the container walls and thus is not a gas at ambient temperature. TF can be very corrosive, especially upon interaction with any water that may be in the system. Although the total pressure of the Vespel ${ }^{\circledR}$ containers remained constant, the composition of the gas became nearly $50 \%$ protium, which reveals that tritium does interact with the Vespel® though it is much more resistant to tritium than UHMW-PE or PTFE. Protium is also produced when EPDM samples were exposed to tritium [4].

Comparing carbon black-filled samples of EPDM with unfilled samples, the change of the glass transition temperature after one year was much greater for the unfilled samples [4]. Normally, EPDM is filled with carbon black.

\section{Considerations for Using Polymers in Tritium Systems}

Based on the results of the studies discussed above, several general considerations for design of systems employing polymers can be identified. 
1) Polymers have unique properties that are commonly used in commercially available components (eg. pumps and valves) and systems that process gases. Many of the chemically resistant polymers and polymers able to withstand extended use at elevated temperature are so-called "halogenated polymers", containing fluorine and chlorine. Unfortunately, the halogenated polymers degrade faster than non-halogenated polymers when exposed to ionizing radiation, including tritium.

2) Solid polymer components can be used in tritium systems, however their properties will degrade with time and tritium exposure will accelerate the degradation. How long a given component will last in a specific application cannot be known precisely until the system is operating. For example, a polymer component in a given type of pump may last much longer in one specific pump than another if one pump is exposed to a significantly greater tritium concentration, partial pressure, or at a higher temperature than another pump of the same type.

3) Strategies to mitigate the degradation of solid polymer components include i) regular testing (leak tightness of valves, leaking of packing, monitoring performance of pumps, etc.), ii) regular preventative maintenance and replacement of polymer components (frequency of replacement determined by monitoring system and maintaining sufficient system performance records), and iii) selecting polymers more resistant to tritium, if practical.

4) Regulators must be aware that the regular replacement of polymeric components is expected and a normal activity in tritium systems. Such replacement is not "off-normal" or an emergency, and should be addressed during system design and establishing operating procedures.

5) In some cases, it may be more cost-effective to replace an entire component than to replace the degrading polymer part only. For example, it may be much easier to replace an entire valve than to rebuild the valve in place in the system merely replacing the valve stem or packing. It also may be more cost-effective to replace an entire pump than to replace an O-ring or seal. These questions must be addressed on a case-by-case basis, and the evaluation must include the time and cost for radiation workers to perform the work.

6) The used polymer components will be radioactive so an approved radioactive waste disposal strategy must be developed. Also, it is highly desirable to not create so-called "mixed waste"radioactive hazardous waste, which is more difficult to dispose of than radioactive waste. Avoiding creating a mixed-waste stream could influence materials selection or component selection. A good rule of thumb is that polymer components exposed in tritium systems contain 10 curies per ec of polymer [5].

7) It is well known that simultaneous exposure of polymers to both ionizing radiation and oxygen significantly increases the rate of degradation of the polymer. This increased rate of radiation damage to polymers with oxygen should not be an issue in most locations in a tritium system since normally they should not contain oxygen to avoid combustion (among other reasons). Other common gases such as argon and nitrogen do not increase the degradation rate of polymers by ionizing radiation (eg. tritium).

8) Polymers more resistant to tritium degradation include polymers having a large concentration of aromatic ring structures (such as the polyimide Vespel ${ }^{\circledR}$ ). Polymers having carbon-halogen bonds (such as PTFE) are much less resistant to tritium degradation. Inert fillers such as carbon black and various forms of glass particles are commonly used to enhance resistance to tritium. To date, a highly aromatic polymer having good elasticity and toughness, which would be an ideal material for sealing applications in tritium systems, has not been found. Highly aromatic polymers (such as Vespel ${ }^{\circledR}$ ) tend to be quite hard and inelastic, which means they are generally problematic sealing materials even though their radiation resistance is good. 
9) Exposing polymers to tritium will result in the radiolytic production of gases and possibly condensable species, liquids, and solids. Protium is a common by-product produced. Halogenated polymers will produce $\mathrm{HCl}$ or $\mathrm{HF}$, which can corrode the system if the amount produced is sufficient and especially if any amount of water vapor is present. Even polymers otherwise more resistant to degradation in tritium will produce protium gas (see Vespel ${ }^{\circledR}$ above). The system design should be able to cope with these species. For example, the protium produced should be able to be removed from the process stream, if protium is undesired in the stream. Cold traps of some kind should be included if a halogenated polymer must be used. Filters should be employed to collect unanticipated debris resulting from polymer degradation.

\section{Oils and Greases}

Oils and greases can be considered to be low molecular weight polymers, so many of the considerations discussed above for polymers apply to oil selection. Oil-based pumps have historically been used in tritium systems. If an oil-based pump is used, the waste stream will likely be mixed waste, because the oil will likely pick up some metal ions that will make the radioactive oil a mixed waste. Mixed waste is more difficult to dispose of properly than radioactive (non-hazardous) waste. Radiation exposure will start to cross-link the oil over time, and it will lose the flow properties that make it the useful lubricant it is. The amount of oil should be as small as possible, or be eliminated if possible. It is likely more important to avoid using oil-based pumps than to avoid polymer-containing components.

Information from the Princeton Plasma Physics Laboratory (PPPL) showed that mechanical pumps were successfully used to pump tritium in their tritium processing system in the TFTR experiment which ran between 1982 and 1997. The pumps used both Krytox ${ }^{\circledR}$ pump oil, a completely fluorinated oil, and hydrocarbon pump oils. PPPL chose Krytox ${ }^{\circledR}$ oil because of its superior thermal and chemical stability and observed no deleterious effects in their operations. They regularly changed both the Krytox ${ }^{\circledR}$ and hydrocarbon pump oil at about three month intervals. The resulting used oil was removed using special systems designed to allow the workers to remove the old oil and add new oil without contacting any surface of the system. Two separate systems ("carts") were used for the Krytox ${ }^{\circledR}$ pumps and the hydrocarbon pumps. From the experience of exposing halogenated polymers to tritium (discussed above), it is surprising that the Krytox ${ }^{\circledR}$ worked so well. Often, the single carbon-halogen (fluorine or chlorine) bond is very susceptible to radiation damage, and tritium fluoride, TF, can form. When TF reacts with water, it becomes extremely corrosive to metals and to glass. The SHINE project should contact Charles Gentile (609) 243-2139 at PPPL for more information.

At PPPL, both types of spent oil were found to contain RCRA hazardous components, and so the oil was treated as mixed waste. The spent oil was fixed using a clay-based product, and finally was disposed of at the Nevada Test Site.

\section{Mechanical Pumps Being Considered}

Considering pumps to replace the Normetex pump, an initial requirement would be that the pump be hermetically sealed. The following pumps are currently being evaluated for tritium service at the Savannah River Site:

1. Busch Scroll FO 0015A (Germany). Seal material is PTFE (Teflon $\left.{ }^{\circledR}\right)$, carbon. Savannah River is attempting to replace the PTFE seal with brass in one test pump.

2. Edwards Scroll nXDS15 (United Kingdom). Seal material is PTFE. Of three available variants: Regular, C - corrosion resistant ("Chemraz ${ }^{\circledR}$ " valves- perfluoro elastomer "FFKM"- Dupont Kalrez ${ }^{\circledR}$ is the prototypical FFKM, stainless steel fittings), and R - without gas ballast). The best 
choice for tritium processing would be either the corrosion resistant version, or better yet the no gas ballast with corrosion resistant materials.

3. AirSquared prototype. The AirSquared company is developing a new scroll pump for Savannah River having either no scroll seal (all metal scrolls like the Normetex pump) or Vespel scroll seals. This pump is not yet available commercially.

4. A possible all-metal pump from Eumeca. This company is newly formed by former employees of Normetex.

\section{Alternative Pumping Schemes}

In the past, mercury has been used in both diffusion pumps in tritium systems and in Toepler mechanical pumps in laboratory systems. Using mercury would be problematic because of health \& safety concerns, however, if the mercury can be trapped and recycled, a mercury system could be a credible alternative to using polymers.

Another potential alternative pumping scheme would employ cold condensation or trapping type pumps. Whether this is practical depends on the gas quantities and flow rates in the tritium system being designed. The ITER project will use various types of cold condensation to pump tritium, and these pumps are being designed now. These systems can be designed without employing polymers or oils of any kind.

\section{$\underline{\text { References }}$}

1. E.A. Clark, K.L. Shanahan. "EFFECTS OF TRITIUM ON UHMW-PE, PTFE, AND VESPEL $®$ POLYIMIDE”, Fusion Science and Technology, 52 (4), (November 2007), pp. 1007-1011.

2. E.A. Clark, G.C. Staack. "EFFECTS OF TRITIUM GAS EXPOSURE ON THE DYNAMIC MECHANICAL PROPERTIES OF EPDM ELASTOMER”, Fusion Science and Technology, 54 (2), (August 2008), pp 576-579.

3. E.A. Clark. "Tritium Effects on Dynamic Mechanical Properties of Polymeric Materials", in Effects of Hydrogen on Materials- Proceedings of the 2008 International Hydrogen Conference. Brian Somerday, Petros Sofronis, Russell Jones, editors, pp 726-734 (2009) ASM International®.

4. E.A. Clark, E.B. Fox, M.C. Kane, G.C. Staack. "Effects of Tritium Gas Exposure on Polymers, Fusion Science \& Technology, 60 (3), pp 1037-1040 (October 2011).

5. E.A. Clark. "WASTE CHARACTERIZATION OF POLYMERIC COMPONENTS EXPOSED TO TRITIUM GAS”. Report WSRC-STI-2008-00078, Savannah River National Laboratory, Westinghouse Savannah River Company, Aiken, South Carolina. OSTI ID 927597 (15 February 2008). 